\title{
Spine layout design for improving food hygiene and reducing travelled distances in a small-scale burger patties processing
}

\author{
${ }^{1}$ Hasnan, N.Z.N., ${ }^{1 * A b}$ Aziz, N., ${ }^{1}$ Taip, F.S. and ${ }^{2}$ Zulkifli, N. \\ ${ }^{I}$ Department of Process and Food Engineering, Faculty of Engineering, Universiti Putra Malaysia, 43400, \\ UPM Serdang, Selangor, Malaysia. \\ ${ }^{2}$ Department of Mechanical and Manufacturing Engineering, Faculty of Engineering, Universiti Putra \\ Malaysia, 43400, UPM Serdang, Selangor, Malaysia.
}

\begin{abstract}
Article history:
Received: 24 October 2018

November 2018

Available Online: 20

November 2018

Keywords:

Cross-contamination,

Food factory layout,

Food processing,

Hygienic layout,

Production efficiency,

Spine layout
\end{abstract}

Received in revised form: 12

Accepted: 15 November 2018

\section{DOI:}

https://doi.org/10.26656/fr.2017.3(4).149

\begin{abstract}
This paper presents a method to perform a spine layout design for a burger patties processing in a rectangular premise measuring $31.5 \times 9 \times 3 \mathrm{~m}$ with a production volume of $300000 \mathrm{~kg} /$ year. The factory experienced cross-contamination, pest infestation, inefficient material and operators flow and excessive moving distance during the production. The mentioned issues can be linked to the poor layout configuration and this consequently leads to incompliance to food safety standards and delay in production time. The poor layout plan is attributed to the lack of knowledge and guideline in designing an efficient and hygienic food plant layout. Hence, a spine layout is proposed in this paper as the company is preparing for the major renovation of the premise. A spine layout consists of a central aisle called "spine" with workstations or rooms located on either side. The central spine was used to conduct the production traffic, whereby food material, utilities and operators could access the different room from the central core. The new layout was able to effectively segregate the high-risk, low-risk processing, transitional and auxiliary's area for 24 rooms, consequently complying with the Good Manufacturing Practice and preventing cross-contamination risk. The travelled distance during the production operation was also reduced by $58.3 \%$ which would lead to the decrease in overall production time and increase in production efficiency.
\end{abstract}

\section{Introduction}

Food processing factory can be understood as a manufacturing system that transforms raw ingredients, by physical or chemical means into marketable food products that can be easily prepared and served by the consumers. Unlike many other design situations, the design of a food factory system is unique. Food is known as perishable items in which their shelf life and quality may be altered by many factors such as temperature, light, humidity, mechanical static and dynamic stress (Saravacos and Kostaropoulos, 2002; Manzini and Accorsi, 2013). Food also contains sensitive components and require considerations on unit operations to prevent nutritional loss. Most importantly, food needs to be significantly safe and hygienic as it is directly consumed by life beings (Hasnan et al., 2014). One of the design elements for the food factory is the layout. It is an important component in the complete design process as it controls the flow of food material and operators when the operation runs once the factory is built (Clark, 2008). The failure to control the material and operator's flow would impact not only the operational efficiency but could also lead to poor sanitation practice (Strano et al., 2012; Benyagoub and Ayat, 2014). In fact, an important impact of poor layout design is the ineffective segregation of work areas that lead to crosscontamination (Lelieveld et al., 2014).

There are several studies on food factory layout that have laid their focus on the hygienic area especially the hygienic zoning and effective segregation between low risk and high-risk area. Smith (2006) had worked on the impact of staff flow, product flow and factory finishes on food hygiene and consequently emphasized the need for a clear guideline to address the hygiene control through production layout for the high-care food processing. Another study by Strano et al. (2012) had developed a series of layout design templates for designing the processing premise of sun-dried prickly pear puree that was aimed to improve food hygiene and workers safety. Bengayoub and Ayat (2014) had investigated the effect of material, waste and operators flow in dairy industries on the cross-contamination and had stated the 
importance of the prerequisite programs with regards to layout for the effective application of Hazard Analysis and Critical Control Points (HACCP). The mentioned studies had not considered the criteria to minimize the production flow in the layout design process, whereby this was, in contrast, the main aim of the layout studies in the production engineering.

There were few layout studies that have involved food processing as the case studies and attempted to minimize production flow and consequently increase the production efficiency. Exemplarily, Amit et al. (2012) had demonstrated the use of the Systematic Layout Planning method and analysis with ARENA simulation to reduce the total travel distance, time, cost and increases output in a snack processing premise. A study by Ojaghi et al. (2015) has generated several layouts using Systematic Layout Planning (SLP) and Graph Based Theory (GBT) for a meatball and soup paste processing. The goal of the study was to determine the sustainable layout that minimizes travel distance, material handling and losses. However, both studies had not given attention to hygiene and food safety requirement that is important for the food industry. Therefore, in fulfilling the current gap for the layout studies in the food industry, the approach of this paper is inspired by the principles of layout design in the field of production engineering on the one hand, and the specific food safety requirement on the other hand.

The study has investigated the use of spine layout configuration for an application in a local food premise as a case study. Yet, this type of layout has not been discussed for food processing in publications as compared to other classic types such as straight-line, "U" shaped and "L" shaped (Clark, 2008; López-Gómez et al., 2009; Rao, 2010). The spine layout was referred to a layout that consists of a main aisle called a "central spine" with workstations (or rooms and departments) located on either side (Langevin et al., 1997). The application of spine layout has been studied in the semiconductor wafer facilities as well as material handling system repeatedly and was able to minimize the total loaded travel distance and consequently increases the operational efficiency (Yang, 1997; Yang et al., 2000; Lin et al., 2004; Montoya-Torres, 2006). An important advantage of the spine layout is the flexibility for future expansion (Jung, 2010). The layout also helps to develop a modular factory which allows segregation of rooms to be done easily and consequently achieve hygiene as well as efficiency in production (A. Kunzelmann, personal communication, April 24, 2015). The layout is also suitable for small, medium and large scaled production and also for any type of products ( R. Jung, personal communication, July 16, 2013).
Based on the mentioned advantages, this paper demonstrates the method to design a food factory layout with the spine configuration. The method was applied to a local case study that produces frozen burger patties with an annual demand of 300000 ton $\mathrm{kg} /$ year. The factory was named as "Factory F" to maintain its anonymity. The resulted layout was evaluated based on the hygienic zoning, personnel and material flow as well as the travelled distance by the operators who were the main carrier for the load in the premise. The finding in this paper is expected to be important in supporting Malaysian local industries especially the small and medium industries (SMEs) in complying Good Manufacturing Practice (GMP) standards which are often required for exporting. At the start-up phase, SMEs with small capital, could not afford to appoint a competent consultant to design their factory (Bellgran and Safsten, 2009; Addy, 2015). They also could not afford to hire highly skilled employees (Baba et al., 2006; Shah Alam et al., 2011; Hasnan et al., 2014). With the limited knowhow, they depend heavily on external bodies such as assistance agencies or research organization to establish a GMP standard factory (Braun and Hadwiger, 2011; Addy, 2015). However, when such bodies are not equipped with a complete guideline on the design implementation, SMEs are not able to be assisted properly (Addy, 2015). This eventually leads them to perform unsystematic planning, trial and error approach, and highly dependent on the non-specialist contractor who also has limited background in food processing (Clark, 2008; Bellgran and Saefsten, 2009; Mat Rani et al., 2014; Addy, 2015). The resulted factories are therefore difficult to meet the GMP requirement and more often lead to unhygienic food operation.

\section{Materials and methods}

\subsection{Factory of the study}

During the time of the study, the production occurred in a premise measuring $31.5 \times 9 \times 3 \mathrm{~m}$ as in Figure 1. The premise was an intermediate unit of a terrace factory (brownfield) that has not been originally designed for food processing. Figure 2 shows the production steps, which began with the receiving of raw materials and proceeded with raw material storage, premixing, flaking, mincing, mixing, forming, slow freezing, packing and shipping. The main facilities involved were the production room, packing room, cold room for the slow freezing process. The storage room was provided for spice storage, dry ingredient storage, raw material cold room and other non-food storage such as utensil and boxes. The storage for packing material was not provided and hence, the cartons were stored in the receiving room. 


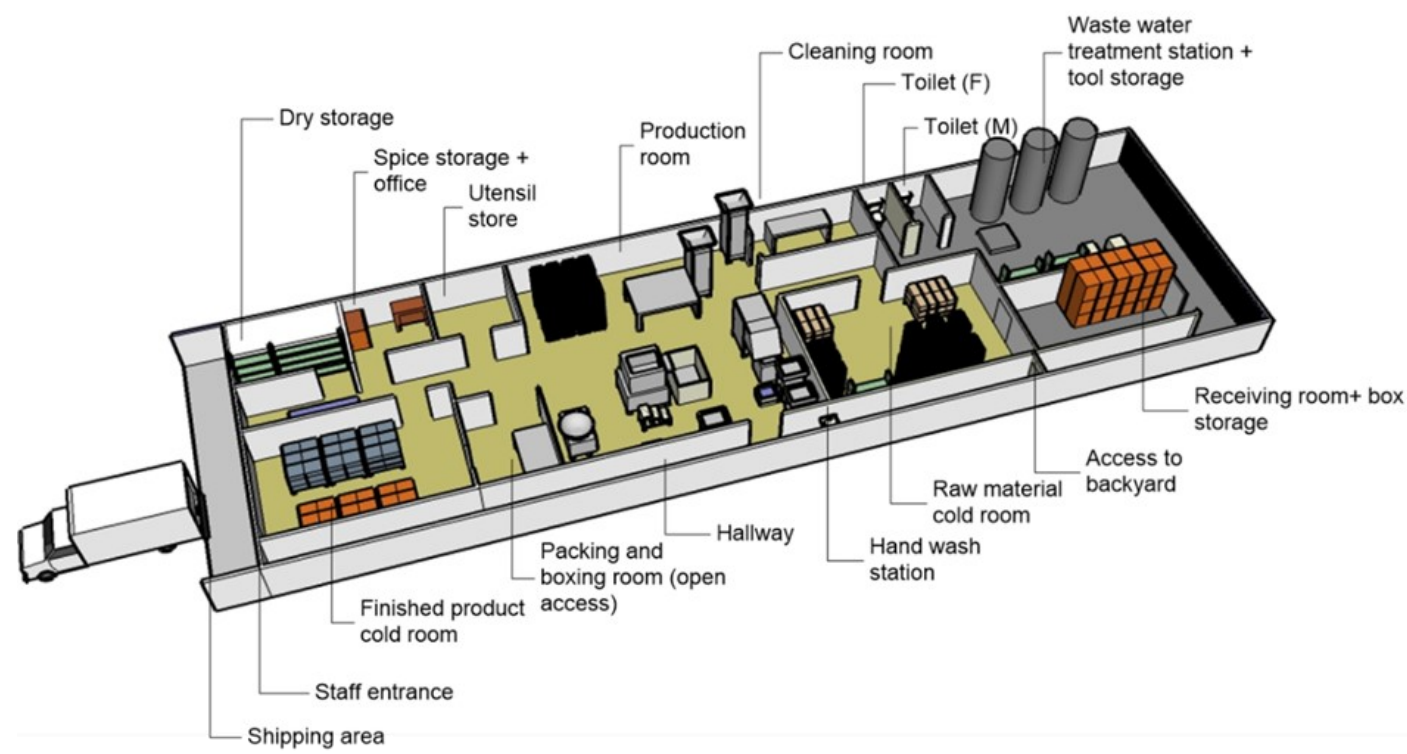

Figure 1. Layout of Factory F

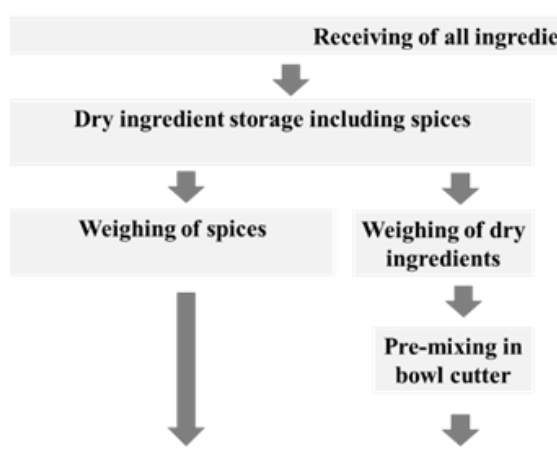

Batch-mixing of all ingredient in paddle mixer

Mincing with mincer

Forming with former machine

Slow freezing in cold room of $-18^{\circ} \mathrm{C}$ ( $\sim 17 \mathrm{~h})$

Packing and boxing on the next morning at $25^{\circ} \mathrm{C}$

Storage of finished products at- $18^{\circ} \mathrm{C}$

Shipping to customer with 2-tonne-truck

Figure 2. Production processes in Factory $\mathrm{F}$

\subsection{Analyses on hygienic zoning, personnel and material flow}

The evaluation on the hygienic design for the layout was carried out based on a review of technical drawings and design specifications ( $\mathrm{H}$. Lelieveld, personal communication, March 25, 2016). The European Hygienic Engineering and Design Group (EHEDG) database has recommended the Hygienic Design Checklist Tool, developed by the American Grocery Manufacturers Association (GMA), to evaluate whether the designs complied with the hygienic design principles. The use of the checklist provides an insight on GMP

design achievability, as the GMA council consisted of a Standards Committee that examines the standard-setting bodies including Codex and ISO for food safety (GMA, 2016). In this study, the two sections in GMA Checklist Tool namely Principle\#1 Distinct Hygienic Zones and Principle\#2 Personnel and Material Flows were used to evaluate the hygienic design of the layout for the existing Factory $\mathrm{F}$ and the new spine layout. Every section had several criteria to be evaluated and scored. The questions were answered by either " $\mathrm{S}$ " for satisfactory, " $\mathrm{M}$ " for design is marginally acceptable, "U" for unsatisfactory or "NA" for requirements is not applicable in that design case. Points were automatically given by the tool based on the answers. A full score shows the hygienic design is satisfactory, while a score of less than $100 \%$ requires the design to be improved (Nikoleiski, 2012).

\subsection{Monitoring analyses}

The result achieved through the score in Section 2.2 was further validated with food hazard analysis in order to check whether the checklist scoring has been performed correctly and produced reliable scores. The food hazard analysis included microbiological analysis and monitoring of physical food hazard. Chemical hazards analysis was not proceed since any risk of chemical contaminant has never occurred. This was supported by no historical record on chemical contaminant from an accredited laboratory previously.

\subsubsection{Microbiological analysis}

The microbiological criteria were tested for air samples and food materials as their unacceptable counts or existence may indicate poor hygienic zoning in the layout and eventually cross-contamination. The tested parameters were aerobic plate count (APC), coliforms, Escherichia coli, Staphylococcus aureus, Salmonella spp. and Listeria spp. The acceptable limit for samples 
was referred to Sun (2012), Schaechter (2009), Sneed et al. (2004), Food Standards Agency (2001) and Yousef and Carlstrom (2003).

\subsubsection{Physical hazard monitoring}

The approach to physical hazard analysis was not given much attention in the literature. The method in this study adopted a visual examination for extraneous material such as metal objects, hard or sharp objects, bone particle, foreign object, insects and repulsive matter (Wilm, 2012). Historical data was also examined including customer complaints on findings of the above hazards. In addition, pest monitoring was performed by locating baits for cockroach and rat at several risky locations for two weeks. These locations were the dry storage, spice storage, production room, packing and boxing room, hallway and receiving room.

\subsection{Analyses on the travelled distance and time}

The travelled distance by the operators was measured on-site at the existing Factory $\mathrm{F}$ during the production operations. The average was determined for the existing layout. In case of the new spine layout, the travelled distance between two room centroids was calculated based on operators' flow following the layout design when travelling between the two rooms (Langevin et al., 1997). The resulted travelled distance was compared and discussed in Section 3.3. By retaining the speed of operators' movement with $17 \mathrm{~kg}$ load as averagely $0.7 \mathrm{~ms}^{-1}$ (measured during the production based on the time taken to complete $10 \mathrm{~m}$ distance), the travelled time should be proportional to the travelled distance.

\subsection{Layout redesign using spine layout method}

The layout design procedure is composed of 5 steps as below:

\subsubsection{Closeness relationship and onward flow in material movement}

This was performed using the closeness relationship analysis where the proximity requirement was indicated by the closeness indices namely, $A$ for absolute necessary, $E$ is especially important, $I$ is important, $U$ is unimportant, and $X$ is undesirable. Consideration of the expected movement frequency between two processes or workstation during the production can assist the closeness relationship analysis (Langevin et al., 1997; Stephens and Meyers, 2013; Heragu, 2016). For example, there is an absolute need for the process "receiving of ingredients" to be located closed to process "ingredients storage". Hence, the close relationship between process "receiving of ingredients" and "ingredients storage" was indexed as $A$. It is undesirable for the "packaging and boxing of finished products" to be located closed to process "receiving of ingredients" as this can lead to cross-contamination from raw materials to the finished products. Hence, this pair of processes is indexed as $X$ for undesirable.

The separation between high-risk area and low-risk area is an obligation (Van Donk and Gaalman, 2004; Holah and Lelieveld, 2011). Low-risk area accommodates the processing activities that take place before the decontamination or kill-step (Holah and Lelieveld, 2011). High-risk area accommodates the processing activities that take place after decontamination or kill-step, where recontamination must be strictly prevented (Lelieveld et al., 2014). This is usually the packing room (Baker et al., 2013).

Additionally, an optimal layout should be able to produce the onward production flow, whereby during the production, the food material and operators are able to move from the receiving area towards the shipping area without having to criss-cross or backtrack. Such flow is able to prevent cross-contamination in the food processing. Therefore, provided with results from the closeness relationship as well as the recommendation to retain the onward flow, the location of the rooms can be predetermined.

\subsubsection{Room listing for the processing operation.}

The next step was to generate the list for the required room in the premise. This required the consideration to separate certain activities by rooming. The provision of individual rooms is recommended if the facilities show the differences in the aspect as in Figure 3.

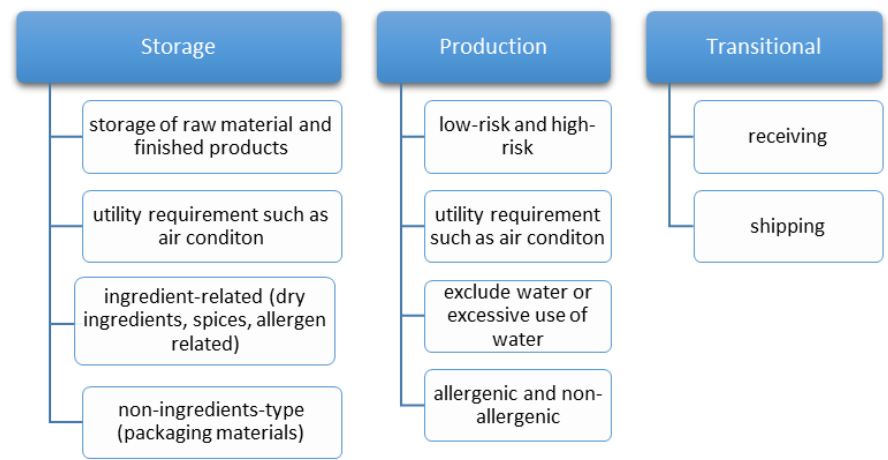

Figure 3. Segregation approach for processing facilities (adapted from Holah and Lelieveld, 2011)

This step results in a Room List. Each room in the Room List is subjected to an individual room planning that covers another intensive design procedure called "Room Planning and Sizing". However, this is not demonstrated in this paper. The important result from the procedure "Room Planning and Sizing" were the 
dimensions of each room which were an important information for Step 4.

\subsubsection{Auxiliary facilities location}

The auxiliary facilities are personnel facilities, laboratories, administration and services (Jung, 2010). Services include utility facilities such as wastewater treatment station, Mand E room, tool storage, chemical storage and other facilities that are not directly related to the production processes. The size of the facilities was also performed using the procedure "Room Planning and Sizing" which is not demonstrated in this paper. As for the auxiliary facilities, the closeness relationship is expected to comply with the hygiene requirements.

1. Personal hygiene facilities (hand wash station and change room) are absolutely important to be adjacent to any production room where operators move from lower risk to higher risk.

2. Laboratory for quality control is important to be adjacent to the processing room that requires a quality test for ease of sampling.

3. Cleaning and washroom for equipment must be close to the processing area.

4. Administration, toilets and service rooms (except for equipment washing) should not be directly adjacent to the processing area and must be segregated via change room and hand-wash station.

Other auxiliary facilities can be positioned on the layout plan based on the movement frequency between the two rooms. At the end of this step, the location of the auxiliary's rooms can be relatively positioned to the production rooms. Yet, their exact location is not known yet at this step.

\subsubsection{Spine plant layout}

The following design constraints and limitations were retained at this step:

- Onward flow from the receiving to shipping area.

- Room segregation requirement
- An adjustment of the individual room size and layout is allowed to a certain extent as to fit the spine aisle and the building shape, as long as not compromising the safety clearance and causes cross-contamination.

Taking into account the mentioned constraints and limitations, the spine layout procedure is commenced as below.

- The receiving area was used as the starting point and proceeded to the adjacent rooms as referred to the closeness relationship.

- When two rooms need to be in adjacency based on closeness relationship in Step 1, they were placed in adjacent on the same side of the central spine. When this was not possible (due to size or movement constraints), they were located at the opposite of the central spine.

- The design process continues in this manner until all rooms were positioned on the layout.

The width of the spine was specified based on traffic density such as the number of operators, material handling equipment size and movement direction.

\section{Results and discussion}

The new spine layout for the Factory $F$ was achieved as in Figure 4. The layout was accommodated on the available floor area about $283.5 \mathrm{~m}^{2}$. Since the premise is an intermediate unit, an expansion space is not available and thus, space reservation for any extension is not useful. Hence, the design has maximized the utilization of the available floor area, whereby $100 \%$ of area is occupied with functional activity from east to the west of the premise. In case of any expansion needed, the factory would need to purchase the next factory lot or increase the capacity of the production machines.

The layout shows that the raw materials storage rooms were arranged along the south side of the spine. The production room was located at the opposite of the storages. The layout has included the design of

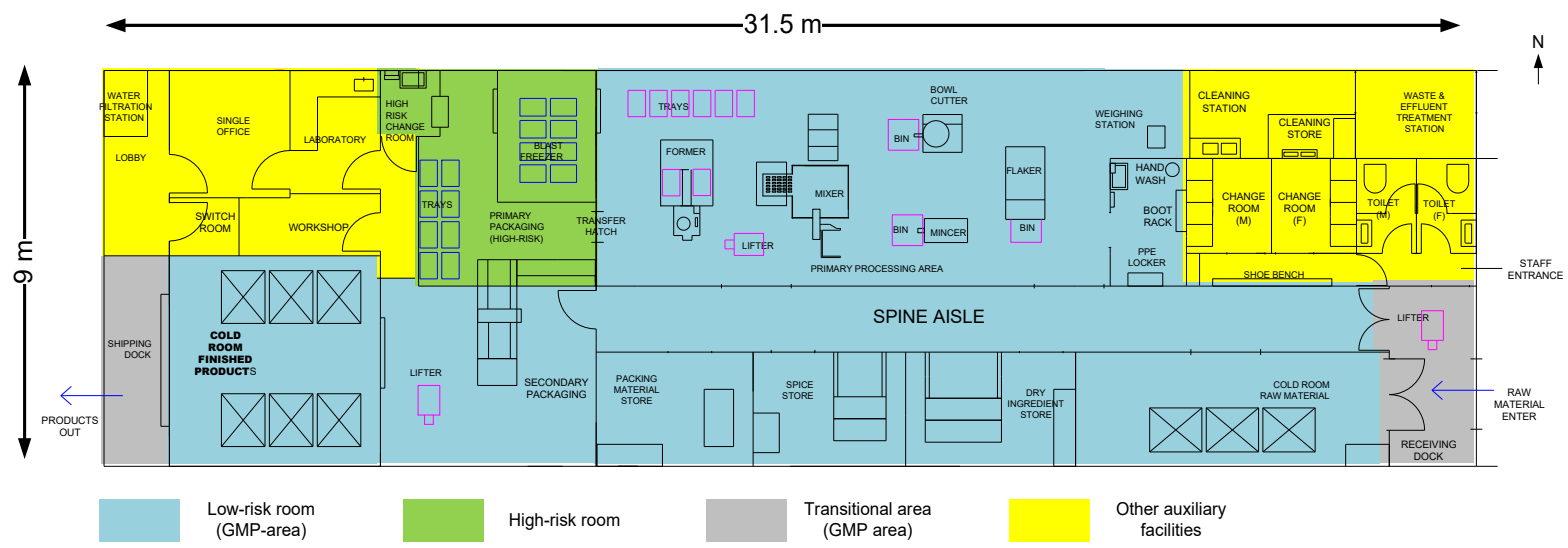

Figure 4. New spine layout for Factory F 
packaging storage which was not available for the existing factory. The central spine was used to conduct the production traffic, whereby material, utilities and operators could access different rooms from the central core. The receiving room was positioned at the east of the building, where all the received raw materials undergo quality control before being allowed to enter the storage rooms. During the production operation, the raw ingredients would be brought to the primary production area for making burger patties. The machines involved are flaker, mincer, bowl cutter, mixer and former. The burger patties would be brought to the blast freezer for rapid freezing in order to reduce the temperature of the patties down to $-22^{\circ} \mathrm{C}$ as this deactivates pathogens.

Upon completing the freezing process, the frozen patties would be retrieved from the blast freezer and packed manually in the primary packaging room that was classified as high-risk (marked as green area in Figure 4). The high-risk room requires the operators to undergo the second change room and hand wash station before entering the room to avoid the recontamination of the frozen patties. The transfer hatch was designed for this room for activities such as removing waste or receiving packing supplies (The transfer hatch must be sanitized in between the two activities). The packed burger patties would then be transferred to the boxing room through conveyor for the cartoning process. All the cartons would then be brought to the cold room for the finished product and ready to be shipped at the west of the building. The overall layout shows an onward production flow for the material and operators movement beginning from the east to the west of the building. The material is able to move onward in a one-way flow from the storage area to production room, packing room, boxing room and lastly shipping without any criss-cross and backward movement. Other auxiliary facilities such as workshop, laboratory, office and other are marked with the yellow area in Figure 4.

\subsection{Effect of layout designs on the hygienic zoning}

The performance of the layout with respect to the hygienic zoning was performed based on the GMA scoring checklist tool in Principle\#1. There were six criteria as in Table 1 that were evaluated for both layouts of the existing Factory $\mathrm{F}$ and for the new spine layout. Factory $\mathrm{F}$ was scored with $35 \%$, while the new spine design obtained $85 \%$. The low mark of the Factory $F$ was due to the complete absence of segregation for the different risk area. Any arrangement related to hygienic zoning was also dismissed. The packing area which was supposed to be classified as a high-risk zone was not segregated and had an open access to production room (Figure 1). This eventually led to the risk of food hazards in the packaging rooms that might contaminate the patties during the packing operation. The expected risk was validated by the findings of the aerobic plate count in air samples at the packing station as $9.7 \times 10^{2} \mathrm{CFU} /$ $\mathrm{m}^{3}$, reaching the counts in production room $1.3 \times 10^{3}$ $\mathrm{CFU} / \mathrm{m}^{3}$. The acceptable level is $0-100 \mathrm{CFU} / \mathrm{m}^{3}$ based on Schaechter (2009). This shows that the packing of fresh patties was performed in an unsafe environment. It was also found that the finished products have unacceptable counts for coliforms $\left(3.4 \times 10^{3}\right.$ and $3.9 \times 10^{3} \mathrm{CFU} / \mathrm{g}$ in two sampling occasions), whereby this was an indicator of poor sanitary environment (Holah and Lelieveld, 2011). Other microbiological parameters were within the acceptable limit.

Furthermore, the current Factory F had no dedicated room for the laboratory and QC activities. This caused some of the research and development tests that involved cooking to be performed in the office room. In addition, the spice storage was combined with the office room which has risked the cross-contamination of spices ingredient with office materials such as metal staples as informed by the operator. The factory was however not equipped with any metal detector. The failure to provide hygienic zoning and facilities segregation can be attributed to incompetent layout design as has been discussed by Van Donk and Gaalman (2004) and Lelieveld et al. (2014). This has also been reported as the common neglect in the food industry that leads to critical cross-contamination and product recall.

The new spine layout design is able to identify the primary packing room as the high-risk area and provides the associated facilities such as high-risk change room and hand wash station. The points were deducted due to the absence of separate laboratories for testing of high risk and low-risk material. Only one laboratory was provided. Yet, during operation, the separation can be done based on time separation for the quality control of high risk and low-risk items. Separation of tools storage is also not available due to space constraint. The separation requirement for the laboratory and tool storage in two different rooms are seen as space consuming which is a challenge to a small premise. This requirement has not been mandatorily required in the local GMP guideline.

\subsection{Effect of layout designs on the personnel and material flow}

The performance of the layouts with respect to the personnel and material flow design was evaluated using Principle\#2 checklist. The principle evaluated four criteria as in Table 2 with an emphasis on the pathway for material, operators and waste that should not cause cross-contamination. Factory $\mathrm{F}$ was scored with $22.5 \%$, 
Table 1. Evaluation of the distinct hygienic zones (Principle\#1)

\begin{tabular}{|c|c|c|c|c|c|c|}
\hline \multirow{2}{*}{ No. } & \multirow{2}{*}{ Criteria } & \multirow{2}{*}{$\begin{array}{l}\text { Available } \\
\text { points }\end{array}$} & \multicolumn{2}{|c|}{ Factory $\mathrm{F}$} & \multicolumn{2}{|c|}{ Spine layout } \\
\hline & & & Score & Points & Score & Points \\
\hline 1.01 & $\begin{array}{l}\text { Facility drawings show hygienic zones, (Ready-to-eat vs. } \\
\text { raw, high care vs. low care, etc.) where applicable. } \\
\text { Hygienic zones should be clearly demarcated on the plant } \\
\text { schematics with colours or other markings to facilitate } \\
\text { easy identification }\end{array}$ & 25.0 & $\mathrm{U}$ & 0.0 & $\mathrm{~S}$ & 25.0 \\
\hline 1.02 & $\begin{array}{l}\text { Separate locker rooms and lunch rooms should exist for } \\
\text { RTE/high risk and non-RTE/lower risk personnel, or } \\
\text { provisions to separate high risk and low-risk employees } \\
\text { exist }\end{array}$ & 25.0 & $\mathrm{U}$ & 0.0 & $\mathrm{~S}$ & 25.0 \\
\hline 1.03 & $\begin{array}{l}\text { Restroom facilities are not located in RTE/high risk zones } \\
\text { (see point } 10.08 \text { ) }\end{array}$ & 25.0 & $\mathrm{~S}$ & 25.0 & $\mathrm{~S}$ & 25.0 \\
\hline 1.04 & $\begin{array}{l}\text { Separate storage areas for tools and spare parts exist to } \\
\text { minimize contamination from non-RTE/lower risk zones } \\
\text { to RTE/ high-risk zones }\end{array}$ & 25.0 & M & 12.5 & M & 25.0 \\
\hline 1.05 & $\begin{array}{l}\text { Separate quality labs should exist for RTE/high risk and } \\
\text { non-RTE/lower risk zones }\end{array}$ & 20.0 & $\mathrm{U}$ & 0.0 & M & 10.0 \\
\hline 1.06 & $\begin{array}{l}\text { Separate storage areas for sanitation crews exist for RTE/ } \\
\text { high risk and non-RTE/lower risk zones (e.g., vacuums, } \\
\text { mops, brooms etc. are segregated) }\end{array}$ & 30.0 & M & 15.0 & $\mathrm{~S}$ & 30.0 \\
\hline & Total points for this principle & 150.0 & & $52.5(35 \%)$ & & $127.5(85 \%)$ \\
\hline
\end{tabular}

while the spine layout with $100 \%$. The low- score of Factory $\mathrm{F}$ is due to the absence of sanitary delivery of material into the high-risk area (packing) and also inefficiency in the waste removal. In addition, any person or operators can freely access the packing area from another low-risk area without going through any hand disinfection. This exposed the unpacked patties to recontamination with the operators coming from production room that dealt with raw ingredients. Another main concern is related to the process step "boxing" that took place in the same area of patties packing. The cartons are brought to the packing area from the receiving room that is not hygienically controlled and is found to be infested with cockroaches. The cartons are stored in the receiving room due to the absence of a cartons storage room. These exposed patties to the risk of pest contamination (Figure 5). The expected risk was validated by the findings of cockroaches and lizards twice during the two-week pest monitoring period at the
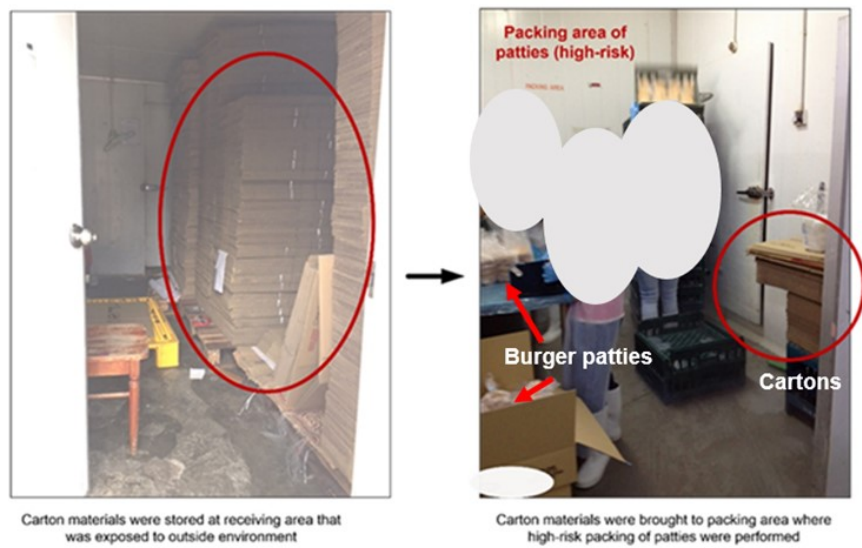

Figure 5. Cross-contamination risk from cartons to patties baits.
The layout in Figure 1 also shows the possible crosscontamination and inefficiency in the production flow. The dry and spice storage were located about $23.72 \mathrm{~m}$ from the receiving area, and the transfer activity had to pass the production hall. This has reduced the effectiveness of the layout in controlling the crosscontamination during the operations as required by the GMP. The required segregation was not met and an onward material flow was not established.

In the spine design, the above issues were addressed. The separate pathway was available for operators working in the low-risk and high-risk area (packing room). The use of transfer hatches is to control the access of material and waste removal from the packing room. The patties can be directly transferred from the blast freezer to the packing room without going through the wet production area. The detailed evaluation is presented in Table 2 .

\subsection{Effect of layout design on production movement}

The spine layout design was found to be able to reduce the travelled distance between two activities (or two rooms). Reduction in travelled distances is shown in Table 3 with the highest reduction obtained for packing material store to the boxing room (87\%) followed by the distance between the dry store and production room $(73 \%)$ as well as dry store and receiving room (67\%). Based on the average of operators moving speed with maximally $17 \mathrm{~kg}$ load in hands being $0.7 \mathrm{~ms}^{-1}$ during the production operation, the reduction of moving distance in the spine layout would be able to decrease the total operators moving time by approximately $58.27 \%$. The 
Table 2. Evaluation of the personnel and material flow design (Principle\#2)

\begin{tabular}{|c|c|c|c|c|c|c|}
\hline \multirow[b]{2}{*}{ No. } & \multirow[b]{2}{*}{ Criteria } & \multirow[b]{2}{*}{$\begin{array}{c}\text { Points } \\
\text { Available }\end{array}$} & \multicolumn{2}{|c|}{ Factory F } & \multicolumn{2}{|r|}{ IFFS } \\
\hline & & & Score & $\begin{array}{c}\text { Points } \\
\text { Awarded }\end{array}$ & Score & $\begin{array}{c}\text { Points } \\
\text { Awarded }\end{array}$ \\
\hline 2.01 & $\begin{array}{l}\text { Facility is designed such that the movement of } \\
\text { employees and visitors throughout the facility is } \\
\text { controlled in a manner that does not contribute to } \\
\text { potential cross-contamination }\end{array}$ & 25.0 & M & 12.5 & $\mathrm{~S}$ & 25.0 \\
\hline 2.02 & $\begin{array}{l}\text { Facility is designed such that the movement of } \\
\text { contractors and maintenance personnel throughout the } \\
\text { facility is controlled in a manner that does not } \\
\text { contribute to potential cross contamination (such as } \\
\text { separate areas) }\end{array}$ & 20.0 & M & 10.0 & $\mathrm{~S}$ & 20.0 \\
\hline 2.03 & $\begin{array}{l}\text { Facility is designed to provide sanitary delivery of } \\
\text { packaging materials, ingredients, and rework into } \\
\text { RTE/ high-risk zones in a manner that does not } \\
\text { contribute to potential cross-contamination }\end{array}$ & 25.0 & $\mathrm{U}$ & 0.0 & $\mathrm{~S}$ & 25.0 \\
\hline 2.04 & $\begin{array}{l}\text { Facility is designed for sanitary removal of trash from } \\
\text { RTE/ high-risk zones (e.g., dedicated personnel/ } \\
\text { travel paths/ dedicated and sanitized footwear for high } \\
\text { to low hygiene areas) }\end{array}$ & 30.0 & $\mathrm{U}$ & 0.0 & $\mathrm{~S}$ & 30.0 \\
\hline & Total points for this section & 100.0 & & $22.5(22.5 \%)$ & & $100.0(100 \%)$ \\
\hline
\end{tabular}

Table 3. Reduction in movement distance between processing rooms

\begin{tabular}{lccc}
\hline \multicolumn{1}{c}{ Movement } & $\begin{array}{c}\text { Distance in Factory F } \\
\text { design (in m) }\end{array}$ & $\begin{array}{c}\text { Distance in spine design } \\
\text { (in m) }\end{array}$ & $\begin{array}{c}\text { Reduction percentage } \\
\text { (in \%) }\end{array}$ \\
\hline Receiving room to raw material cold room & 5.04 & 2.00 & 60 \\
Receiving room to dry store & 23.72 & 7.80 & 67 \\
Receiving room to spice store & 22.17 & 13.60 & 19 \\
Raw material cold room to production room & 3.5 & 3.45 & 1 \\
Dry store to production room & 5.60 & 1.50 & 73 \\
Spice store to production room & 3.59 & 2.20 & 39 \\
Packing material store to packing room/ & 4.40 & 2.80 & 36 \\
station & 22.66 & 2.96 & 87 \\
Packing material store to boxing room & 3.03 & 2.70 & 10 \\
Boxing room/station to finished product & 88.67 & 37.01 & 58.26 \\
cold room & & \\
\hline Total & & & \\
\hline
\end{tabular}

reduction was able to be achieved as the procedure has analysed the closeness relationship between processing activities. Additionally, the central spine was able to provide a direct and shortened access for most facilities. This decreases the overall production time and benefits the health of the operators.

\section{Conclusion}

The present study provides an insight into the faulty layout designs in a small frozen food factory in Malaysia, identified as Factory F. The overall results showed that the premise has critical design issues that violated the GMP requirements. The findings of food hazard such as microbes, pests and metals had affected the quality and safety of products. The incompliance to GMP has slimmed the chance for the factory to be accepted in the premium market. The study has also provided the know-how for achieving the hygienic and production-efficient layout through the spine design. This is especially significant for SMEs since they are in serious need for a concrete design information and could not afford consultants, researches, and skilled employees. Such additional guidelines would help to remove the confusion, misinterpretation and neglect in hygienic aspects. Additionally, the procedure was able to reduce the required moving distance of operators during the production operation. This could reduce the total production time and help the factory to meet customer deadlines in a shorter time.

Factory $\mathrm{F}$ has shown commitment to improving the design error which is currently being carried out at the premise. It is recommended that another round of food hazard analyses to be carried out after the retrofit is complete. The cost of infrastructure improvement was, however, high due to the repair need and reconstruction. It is therefore emphasized that the implementation of a competent layout has to be taken at the design stage to prevent such additional cost.

\section{Acknowledgements}


This research was funded by a grant from the Universiti Putra Malaysia (9399813) and Knowledge Transfer Program (6228148). The authors would like to acknowledge the support given by the case study of SME manufacturer in providing access to the real data on-site.

\section{References}

Addy, R. (2015). Food Factory Design Can Beat Safety Threat. Retrieved on June 21, 2018 from Food Manufacture Website: http:// www.foodmanufacture.co.uk/Food-Safety/Foodsafety-problems-can-crop-up-in-plant-design.

Amit, N., Suhadak, N., Johari, N. and Kassim, I. (2012). Using simulation to solve facility layout for food industry at XYZ Company. 2012 IEEE Symposium on Humanities, Science and Engineering Research, 24-27 June 2012. Kuala Lumpur, Malaysia: IEEE. https://doi.org/10.1109/SHUSER.2012.6268900

Baba, D.M., Mohd Yusof, S.R. and Azhari, Salleh, M. (2006). A benchmarking implementation framework for automotive manufacturing SMEs. Benchmarking: An International Journal, 13(4), 396-430. https:// doi.org/10.1108/14635770610676272

Baker, C. (2013). Handbook of Food Factory Design. New York: Springer. https:// doi.org/10.1007/978-1-4614-7450-0

Bellgran, M. and Säfsten, E.K. (2009). Production development: design and operation of production systems. $1^{\text {st }}$ ed. Heidelberg: Springer.

Braun, S. and Hadwiger, K. (2011). Knowledge transfer from research to industry (SMEs)-An example from the food sector. Trends in Food Science and Technology, 22, 90-96. https://doi.org/10.1016/ j.tifs.2011.03.005

Clark, J.P. (2008). Practical design, construction and operation of food facilities. New York: Academic Press.

Food Standards Agency. (2001). Meat Hazard Analysis and Critical Control Point Regulations 2002 (No. 889). Retrieved from http://www.legislation.gov.uk/ uksi $/ 2002 / 889 /$ made

Grocery Manufacturers Association (GMA). (2016). Board, Councils and Committees. Retrieved on July 20, 2018 from GMA Website: http:// www.gmaonline.org/about/board-councilscommittees/

Hasnan, N.Z.N., Aziz, N.A., Zulkifli, N. and Taip, F.S. (2014). Food factory design: reality and challenges faced by Malaysian SMEs. Agriculture and Agricultural Science Procedia, 2, 328-336. https:// doi.org/10.1016/j.aaspro.2014.11.046

Holah, J. and Lelieveld, H.L. (2011). Hygienic design of food factories. Cambridge: Woodhead Publishing Limited. https://doi.org/10.1533/9780857094933

Jung, R. (2010). Fabrikplanung. Sigmaringen: AlbstadtSigmaringen University

Langevin, A., Montreuil, B. and Riopel, D. (1997). Spine layout design. The International Journal of Production Research, 32(2), 429-442. https:// doi.org/10.1080/00207549408956942

Lelieveld, H.L., Holah, J. and Napper, D. (2014). Hygiene in food processing: principles and practice. Cambridge: Woodhead Publishing Limited.

Lin, J.T., Wang, F.K. and Young, J.R. (2004). Virtual vehicle in the connecting transport automated material-handling system (AMHS). International Journal of Production Research, 42(13), 2599-2610. https://doi.org/10.1080/00207540410001671624

López-Gómez, A., Fernández, P.S., Palop, A., Periago, P.M., Martinez-López, A., Marin-Iniesta, F. and Barbosa-Cánovas, G.V. (2009). Food safety engineering: an emergent perspective. Food Engineering Reviews, 1(1), 84-104. https:// doi.org/10.1007/s12393-009-9005-5

Manzini, R. and Accorsi, R. (2013). The new conceptual framework for food supply chain assessment. Journal of Food Engineering, 115(2), 251-263. https://doi.org/10.1016/j.jfoodeng.2012.10.026

Ministry of Health (MOH) Malaysia. (2012). Annual report 2010. Retrieved on May 15, 2018 from MOH Website: http://www.moh.gov.my/images/gallery/ publications/md/ar/2010.pdf.

Montoya-Torres, J.R. (2006). A literature survey on the design approaches and operational issues of automated wafer-transport systems for wafer fabs. Production Planning and Control, 17(7), 648-663.

Nikoleiski, D. (2012). Principles of hygienic design. Journal of Hygienic Engineering and Design, 1, 1518.

Ojaghi, Y., Khademi, A., Yusof, N.M., Renani, N.G. and Syed Hassan, S.A.H. (2015) Production layout optimization for small and medium scale food industry. Procedia CIRP, 26, 247-251. https:// doi.org/10.1016/j.procir.2014.07.050

Rani, R.M., Ismail, W.R. and Ishak, I. (2014). An integrated simulation and data envelopment analysis in improving SME food production system. World Journal of Modelling and Simulation, 10(2), 136147.

Rao, D.G. (2010). Fundamentals of Food Engineering. New Delhi: PHI Learning Pvt. Ltd.

Saravacos, G.D. and Kostaropoulos, A.E. (2002). Handbook of Food Processing Equipment. New York: Springer. https://doi.org/10.1007/978-1-4615- 
0725-3

Schaechter, M. (2009). Encyclopedia of Microbiology. San Diego: Academic Press.

Shah Alam, S., Mohd Jani, M.F., Che Senik, Z. and Ahmad Domil, A.K. (2011). Assessing Barriers of Growth of Food Processing SMIs in Malaysia'. International Business Research, 4, 252-259.

Smith, D. (2006). Design and management concepts for high care food processing. British Food Journal, 108 (1), 54-60. https:// doi.org/10.1108/00070700610637634

Sneed, J., Strohbehn, C., Gilmore, S. and Mendonca, A. (2004). Microbiological evaluation of foodservice contact surfaces in Iowa assisted-living facilities. Journal of the American Dietetic Association, 104 (11), 1722-1724. https://doi.org/10.1016/ j.jada.2004.08.026

Strano, L., Russo, P., Lanteri, P. and Tomaselli, G. (2012). Defining the environmental and functional characteristics of the buildings used to produce prickly pear dried puree in terms of food hygiene and safety. Food Control, 27(1), 170-177. https:// doi.org/10.1016/j.foodcont.2012.03.012

Sun, D. (2012). Handbook of Food Safety Engineering. West Sussex: Blackwell Publishing Ltd.

Van Donk, D.P. and Gaalman, G. (2004). Systematic Layout Planning of Food Process. Chemical Engineering Research and Design 82(11): 14851493. https://doi.org/10.1205/cerd.82.11.1485.52037

Wilm, K.H. (2012). Foreign Object Detection: Integration in Food Production. Retrieved on August 1, 2018 from Food Safety Magazine Website: http:// www.foodsafetymagazine. com/magazine-archive1/ octobernovember-2012/testing-foreign-objectdetection-integration-in-food-production/

Yang, T. and Peters, B.A. (1997). A spine layout design method for semiconductor fabrication facilities containing automated material-handling systems. International Journal of Operations and Production Management, 17(5), 490-501. https:// doi.org/10.1108/01443579710167212

Yang, T., Su, C.T. and Hsu, Y.R. (2000). Systematic layout planning: a study on semiconductor wafer fabrication facilities. International Journal of Operations and Production Management, 20(11), 1359-1371. https:// doi.org/10.1108/01443570010348299

Yousef, A. and Carlstrom, C. (2003). Food Microbiology. New Jersey: John Wiley and Sons. 